\title{
BIOACTIVITIES OF THE ETHYL ACETATE EXTRACT OF RHODOCOCCUS QINGSHENGII STRAIN BJC15-A38 AN ENDOPHYTE OF AZADIRACHTA INDICA A. JUSS
}

\author{
PREETI SAINI ${ }^{1}{ }^{*}$, MADHURAMA GANGWAR ${ }^{1}$, AMRINDER KAUR ${ }^{2}$ \\ 1Department of Microbiology, Punjab Agricultural University, Ludhiana 141004, ${ }^{2}$ Department of Plant Pathology, Punjab Agricultural \\ University, Ludhiana 141004 \\ Email: saini.preeti7777@gmail.com
}

Received: 09 Jul 2016 Revised and Accepted: 20 Apr 2017

\begin{abstract}
Objective: This study evaluated the antidiabetic activities of the ethyl acetate-methanol (4:1) extract (EA) of Rhodococcus qingshengii strain BJC15A38 supernatant.

Methods: In vitro alpha-amylase and alpha-glucosidase inhibitory assays, were used to determine the antidiabetic activity of $E A$ (100, $250,500,750$ and $1000 \mu \mathrm{g} / \mathrm{ml}$ ). Also, the total phenol content of the extract was determined, followed by understanding the mode of $\alpha$-amylase inhibition.

Results: The crude extract from Azadirachta indica A. Juss. endophytic actinomycete Rhodococcus qingshengii strain BJC15-A38 was found to have significant inhibition against $\alpha$-amylase ( IC $_{50}=65.93 \mu \mathrm{g} / \mathrm{ml}$ ) and $\alpha$-glucosidase (IC ${ }_{50}=929.56 \mu \mathrm{g} / \mathrm{ml}$ ). The total phenol content of the crude was found to be $97.25 \pm 6.47$ and $15.40 \pm 0.43 \mathrm{mg} / \mathrm{g}$ of the extract in terms of catechol and gallic acid equivalents respectively. Purification of the extract was carried out using silica gel column chromatography. Kinetic analysis revealed the mixed competitive with mixed competitive of inhibition towards $\alpha$-amylase.
\end{abstract}

Conclusion: The findings suggest that the extract of Rhodococcus qingshengii strain BJC15-A38 possesses antidiabetic effects.

Keywords: Alpha-amylase, Alpha-glucosidase, Azadirachta indica A. Juss., Diabetes mellitus, Rhodococcus qingshengii strain BJC15-A38, Total phenol

(C) 2017 The Authors. Published by Innovare Academic Sciences Pvt Ltd. This is an open access article under the CC BY license (http://creativecommons.org/licenses/by/4.0/) DOI: http://dx.doi.org/10.22159/ijpps.2017v9i6.14389

Diabetes mellitus (DM) is the highest cause of deaths among other chronic diseases [1]. Type-2 diabetes is complicated by several factors inherent in the disease process, routinely, insulin resistance, hyper-insulinemia, impaired insulin secretion and reduced insulinmediated glucose uptake and utilization. Oxidative stress occurs at an early stage in diabetes, preceding the appearance of complications such as cardiovascular disease, kidney failure, blindness, impotence, and gangrene [2]. DM thus cannot be cured but can be controlled through maintenance of blood glucose levels within normal ranges $(80-120 \mathrm{mg} / \mathrm{dl})$.

Herbal and natural products of folk medicine have been used for millennia in every culture throughout the world. In Indian traditional medicinal system, the use of Azadirachta indica for centuries is such an example. The bark, seeds, leaves, fruit, extracts and oils of $A$. indica tree contain pharmacological constituents which offer some impressive therapeutic qualities, like anti-helminthic, anti-inflammatory, antimicrobial, antipyretic and anti-tumor activities [3-6]. Further, it leads to regeneration of insulin-producing cells and a corresponding increase in the plasma insulin [7].

Each and every part of $A$. indica has been reported to retain one or other form of microbiota [8-10]. The endophytes obtained from $A$. indica plant have been widely studied for their antimicrobial $[4,10]$, anticancer [11] and insecticidal activities [12]. This validates the fact that endophytes sustain the properties which are existent in their host. Thus the present study targets to screen an endophytic actinomycete Rhodococcus qingshengii strain BJC15-A38 from $A$. indica for its ability to produce bioactive secondary metabolites against starch hydrolyzing enzymes.

All the chemicals and reagents used in the investigation were of analytical grade. Alpha-amylase, starch, dialysis membrane and dinitro salicylate reagent were purchased from HiMedia Laboratories Pvt. Ltd., Mumbai. A few chemicals, including $\alpha$-glucosidase and pnitrophenyl- $\alpha$-D-gluco pyranoside substrate, were obtained from SRL Chemicals and others were purchased from Loba Chemicals. The isolate Rhodococcus qingshengii strain BJC15-A38 was obtained from the Department of Microbiology, Punjab Agricultural University, Ludhiana and was maintained on starch casein agar slants at $4{ }^{\circ} \mathrm{C}$. It had reportedly been recovered from shoot tissues of a randomly selected healthy $A$. indica tree and had been characterized previously on the basis of $16 \mathrm{~S}$ rDNA sequencing [13]. The fermentation was carried out in $500 \mathrm{ml}$ starch casein broth in a $1000 \mathrm{ml}$ Erlenmeyer flask followed by incubation for $7 \mathrm{~d}$ in a rotary shaker (200 rpm) at 28 ${ }^{\circ} \mathrm{C}$. After fermentation, the broth was centrifuged at 10,000 rpm for 15 min at $10{ }^{\circ} \mathrm{C}$ and the cell mass was discarded. The supernatant was extracted twice with ethyl acetate: methanol (4:1). The extract was then lyophilized using a freeze dryer at-130 ${ }^{\circ} \mathrm{C}$. Different concentrations of $E A$ were made by weighing the crude material obtained after lyophilization. Five different concentrations viz. 100, $250,500,750$ and $1000 \mu \mathrm{g} / \mathrm{ml}$ of $E A$ were prepared by dissolving in dimethyl sulfoxide (10\% DMSO in distilled water). The preparations were stored in airtight container at $4{ }^{\circ} \mathrm{C}$ for further use.

The $\alpha$-amylase and $\alpha$-glucosidase inhibitory activities were examined according to previous workers $[14,15]$, using Systronics ${ }^{\circledR}$ Double beam Spectrophotometer 2203smart. Total phenolic content was assayed according to the Folin-Ciocalteau method [16] and expressed as $\mathrm{mg} / \mathrm{g}$ catechol and gallic acid equivalents. A simple model system was used to evaluate the effects of $E A$ on glucose movement in vitro. It involved a sealed dialysis tube into which a solution of glucose and sodium chloride $(0.15 \mathrm{M})$ was introduced and the appearance of glucose in the external solution was measured [17].

The $E A$ concentrates were dry charged onto the chromatography instrument with 60-120 mesh size silica gel column (250 g). The column was sequentially eluted with chloroform and ethanol mixture (95:5, 90:10, 85:15, 80:20, 75:25, 70:30, 65:35, 60:40 and $55: 45)$ and the fractions monitored spectrophotometrically. Fractions showing inhibitory activity were pooled together. The

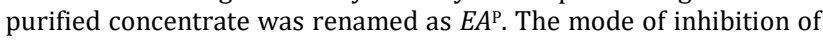
$\alpha$-amylase by $E A^{\mathrm{P}}$ was conducted using the modified method described by Narkhede [14]. The amount of reducing sugars 
released was determined calorimetrically using a maltose standard curve and converted to reaction velocities. The type (mode) of inhibition of the crude extract on $\alpha$-amylase activity was determined by analysis of the double reciprocal (Line weaver-Burk) plot using Michaelis-Menten kinetics [18].

Percentage inhibition was calculated as under:

$$
\text { Inhibition }(\%)=\frac{\text { Control-Test }}{\text { Control }} \times 100
$$

Data were presented as a mean \pm standard deviation (SD) and analyzed using CPCS1 software developed by Department of Mathematics, Statistics, and Physics, PAU, Ludhiana. The P value of $<0.05$ was considered as statistically significant. The graph was plotted in Microsoft Excel 2007. The concentration of the extract that caused $50 \%$ inhibition was calculated using regression analysis.

Only $5 \%$ of carbohydrate digestion occur in the mouth, with amylase secreted by salivary glands. This process is halted in the stomach due to the high acid environment that destroys the amylase activity. When food enters the intestine, acidic $\mathrm{pH}$ is neutralized by pancreatic bicarbonate and mucous that lines the walls of the intestine. Amylase is secreted into the small intestines by the pancreas. Inhibitors of $\alpha$-amylase delay the breaking down of carbohydrate in the small intestine and diminish the postprandial blood glucose excursion in a person suffering from diabetes [19]. So there is a need to search for alternative drugs from medicinal plants with increased potency and lesser adverse effects than existing drugs $[20,21]$. In this study, the effect of $E A$ obtained from endophytic actinomycete isolate on the activities of $\alpha$-amylase and $\alpha$-glucosidase was evaluated. The inhibitory activity of different concentrations of $E A(100-1000 \mu \mathrm{g} / \mathrm{ml})$ on $\alpha$-amylase ranged from 29.65 to $48.96 \%$, whereas for $\alpha$-glucosidase it ranged from 16.44 to $59.32 \%$ (table 1 ). The results showed that the $\alpha$-amylase activity was more prominent at concentrations lesser than $100 \mu \mathrm{g} / \mathrm{ml}$ than higher concentrations. The $\mathrm{IC}_{50}$ value of the test isolate was found to be $65.93 \pm 0.44 \mu \mathrm{g} / \mathrm{ml}$. On the contrary, a dose-dependent increase in inhibition percent was observed in the case of $\alpha$-glucosidase. The 50 $\%$ inhibitory concentration of the extract was recorded to be $929.56 \pm 0.13 \mu \mathrm{g} / \mathrm{ml}$.

Table 1: Anti starch degrading activities of $E A$ expressed as inhibition percentages

\begin{tabular}{|c|c|c|}
\hline \multirow[t]{2}{*}{ Concentration $s(\mu \mathrm{g} / \mathrm{ml})$} & \multicolumn{2}{|c|}{ Antidiabetic activity (\%) } \\
\hline & $\alpha$-amylase a & $\alpha$-glucosidase a \\
\hline$E A 100$ & $48.96 \pm 0.00$ & - \\
\hline$E A 250$ & $36.57 \pm 0.04$ & - \\
\hline$E A 500$ & $33.09 \pm 0.03$ & $16.44 \pm 0.00$ \\
\hline EA750 & $29.65 \pm 0.00$ & $30.15 \pm 0.04$ \\
\hline EA1000 & - & $59.32 \pm 0.00$ \\
\hline
\end{tabular}

${ }^{\text {a mean }} \pm \mathrm{SD},(n=3)$.

This is in line with reports of Prabavathy and Valli Nachiyar [22]. Alphaamylase inhibitors from plant endophytic fungus Syncephalastrum sp. had been shown to have a strong inhibitory activity against $\alpha$-amylase however the mode of inhibition was competitive. In a study, 70 endophytic actinomycetes associated with medicinal plants when checked for $\alpha$-amylase inhibitory activity revealed that 19 of the strains were secreting $\alpha$-amylase inhibitor extracellularly while 16 produced intracellular $\alpha$-amylase inhibitor [23]. These results are also consistent with Lestari et al. [24], who isolated endophytic actinomycete Streptomyces sp. IPBCC. B.15.1539 from Tinospora crispa, a Thai medicinal herb. The $\mathrm{IC}_{50}$ for the ethyl acetate extract was $0.047 \mu \mathrm{g} / \mathrm{ml}$. Also, when the ethyl acetate extract was applied in vivo, it lowered blood glucose levels in streptozotocin mice by $26 \%$.

It appears that this effect is associated with polyphenols present in $E A(97.25 \pm 6.47$ and $15.40 \pm 0.43 \mathrm{mg} / \mathrm{g}$ of the extract in terms of catechol and gallic acid equivalents). The presence of phenol entities has previously been related to anti-hyperglycemic activity $[25,26]$. In a study, 17 different compounds were identified from the leaf extract of Croton bonplandianum. Out of these, E-15 heptadecanol, 1- nonadecene, 5-eicosene, asparagines, 2-tetradecene, cyclotetracosane had been held responsible for their anti-diabetic and alpha-amylase inhibitory activity [27].

The importance of this study lies in the fact that along with the reduction in total sugar content in the reaction mixture, the extract was also able to prevent its diffusion back into the medium across the semipermeable membrane (table 2). This validates that the diffusion of monosaccharide is one of the modes involved in inhibiting the starch degrading enzymes by endophytic actinomycetes. This means that if such a compound is used in biological systems, it will lead to an overall decrease in the intracellular glucose content, thereby reducing the secondary effects (retinopathy, neuropathy) witnessed in its presence. Additionally, since the effects were observed up to $24 \mathrm{~h}$ thus, it could be a source of daily antidiabetic dose. Previously, it was reported that Eugenia jambolana (Syn. S. cumini) aqueous extracts were inhibiting diffusion of glucose across the dialysis membrane. The diffusion was recorded to be $54.33 \%$ and $44.76 \%$ at 60 and 120 -minute interval. It effectively inhibited the diffusion of glucose for $150 \mathrm{~min}$ [28].

Table 2: Effect of $E A$ on the movement of glucose out of dialysis tube over $24 \mathrm{~h}$ incubation period expressed as inhibition percentages

\begin{tabular}{lllll}
\hline Hour & $\boldsymbol{E A}$ concentration $(\boldsymbol{\mu g} / \mathbf{m l})$ & $\boldsymbol{E A 5 0 0}^{\mathbf{a}}$ & $\boldsymbol{E A 7 5 0}^{\mathbf{a}}$ \\
\cline { 2 - 5 } & $\boldsymbol{E A 1 0 0}^{\mathbf{a}}$ & $\boldsymbol{E A 2 5 0}^{\mathbf{a}}$ & $51.60 \pm 2.58$ & $46.68 \pm 6.10$ \\
$1^{\text {st }}$ & $20.66 \pm 2.34$ & $32.50 \pm 3.29$ & $48.09 \pm 7.98$ & $44.55 \pm 3.62$ \\
$3^{\text {rd }}$ & $5.68 \pm 2.66$ & $40.91 \pm 1.74$ & $20.60 \pm 3.90$ & $39.23 \pm 3.49$ \\
$2^{\text {th }}$ & - & - & $8.89 \pm 0.65$ & $35.65 \pm 1.95$ \\
$2^{\text {nd }}$ & - & - & - & $34.40 \pm 0.78$ \\
$2^{\text {th }}$ & - & - & 30.14 & $3.69 \pm 3.62$ \\
\hline
\end{tabular}

amean $\pm \mathrm{SD},(n=3)$.

This is the first report pertaining to a kinetic study of an endophytic actinomycete purified extract from $A$. indica A. Juss against $\alpha$-amylase. A total of 9 fractions was obtained after the completion of the column chromatography technique. It was observed that $\alpha$-amylase inhibitory activity was present only in the initial fractions. The inhibition percentage was $16.33 \pm 0.76,19.30 \pm 0.09$ and $0.99 \pm 0.03 \%$ for fractions eluted by the chloroform-ethanol ratio of 95:5, 90:10 and 85:15 respectively. This indicated towards the non-polar nature of inhibitory compounds since the initial eluting solvents were composed of higher chloroform to ethanol ratios. The reason behind this is the polar 
nature of silica gel itself. More polar components have an affinity to polar silica gel and thus travel short distances.

Lineweaver-Burk plot designed by using the Michaelis-Menten equation showed that extracts of this indefinite inhibited $\alpha$-amylase in a mixed competitive way. As indicated in fig. 1, Michaelis-Menten constant for the control was- $0.09 \mathrm{mmol}$, which changed to- 0.11 mmol after addition of the inhibitor. On the other hand, maximum velocity exhibited a decrease of 0.07 units $(0.052$ and 0.045 $\mathrm{mmol} / \mathrm{min}$ before and after the addition of $E A^{\mathrm{P}}$ ).

Likewise, the mode of the antidiabetic activity of crude extract of Physalis peruviana fruits was investigated [29]. The results revealed that it was able to carry out the inhibition of $\alpha$-amylase, $\alpha$-glucosidase, and maltase; in non-competitive, mixed, competitive manners respectively. The Vmax and $\mathrm{Km}$ values for the mixed mode of inhibition indicated a change of 0.004 $\mathrm{mmol} / \mathrm{min}$ and-1.667 respectively, after the addition of an inhibitor, when observed using Lineweaver-Burk plot. In the case of competitive inhibition, $\mathrm{Km}$ was 1.110 in control which changed to 7.087 in addition of the crude extract, whereas Vmax remained constant $(0.009 \mathrm{mmol} / \mathrm{min})$. On the other hand, $\alpha$ amylase inhibition, which was of the non-competitive type indicated decreases in Vmax and $\mathrm{Km}$ values by $0.004 \mathrm{mmol} / \mathrm{min}$ and 0.158 respectively on the addition of the extract. However, no such kinetic study is available pertaining to the starch degrading enzyme inhibition by endophytic actinomycetes.
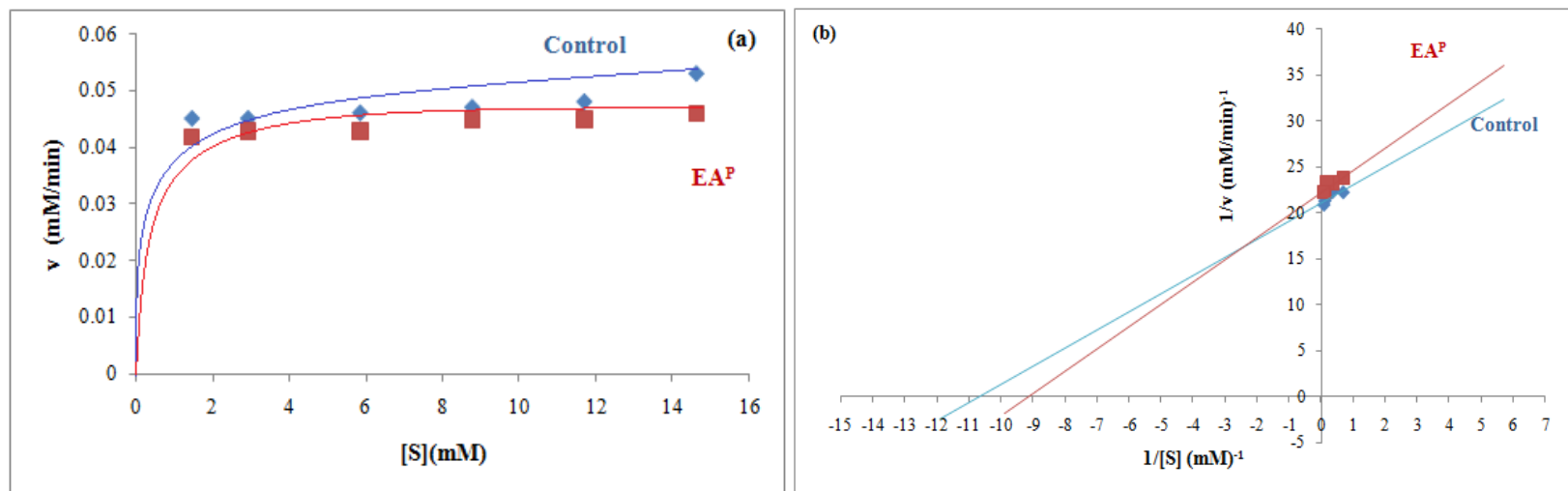

Fig. 1: Mode of inhibition of $\alpha$-amylase by ethyl acetate extract of Rhodococcus qingshengii strain BJC15-A38, (a) Michaelis-Menten plot and (b) Lineweaver-burk plot

Thus, phenolic entities present in the EA extract of endophytic actinomycete Rhodococcus qingshengii strain BJC15-A38 from Azadirachta indica A. Juss. had exhibited significant antidiabetic activity as compared to control, in vitro as well as through a semipermeable membrane, through competitive mode. It revealed that just like host plants, their endophytes are also capable of combating the negative effects of chronic diseases. Further studies are required to evaluate their effects in the living model systems.

\section{CONFLICT OF INTERESTS}

The authors declare that thereis no conflict of interests.

\section{REFERENCES}

1. WHO. Available from: www.who.int/mediacentre/factsheets/ fs312/en/ 2014. [Last accessed on 20 Jun 2016]

2. Haldar PB, Rupeshkumar M, Kavitha K. Role of herbal plants in diabetes mellitus therapy: an overview. Int J Appl Pharm 2014;6:1-3.

3. Gopal R, Gnanakalai K. Phytochemical constituents and in vitro antibacterial activity of various extracts of Azadirachta indica (Neem). Int J Curr Pharm Res 2016;8:52-5.

4. Verma VC, Gond SK, Mishra A, Kumar A, Kharwar RN, Gange AC. Endophytic actinomycetes from Azadirachta indica A. Juss.: Isolation, diversity and anti-microbial activity. Microb Ecol 2009;57:749-56.

5. Shenpagam HN, Kanchana DD, Sinduja G, Sandhya R. Isolation of endophytic actinomycetes from medicinal plants and its mutational effect in biocontrol activity. Int J Pharm Sci Res 2012;3:4338-44.

6. Patil PR, Patil SP, Mane A, Verma S. Antidiabetic activity of alcoholic extract of neem (Azadirachta indica) root bark. Natl J Physiol Pharm Pharmacol 2013;3:142-6.

7. Bhat M, Zinjarde SS, Bhargava SY, Kumar AR, Joshi BN. Antidiabetic Indian plants: a good source of potent amylase inhibitors. J Evidence-Based Complementary Altern Med 2011. http://dx.doi.org/10.1093/ecam/nen040

8. George S, Vincent S. Comparative efficacy of Annona squamosa Linn. and Pongamia glabra Vent. to Azadirachta indica A. Juss against mosquitoes. J Vector Borne Dis 2005;42:159-63.
9. Verma VC, Gond SK, Kumar A, Kharwar RN, Strobel GA. Endophytic mycoflora of bark, leaf and stem tissues of Azadirachta indica A. Juss. (Neem) from Varanasi (India). Microb Ecol 2007;54:119-25.

10. Arun Kumar G, Robert Antony AV, Kannan R. Exploration of endophytic microorganisms from selected medicinal plants and their control potential to multi-drug resistant pathogens. J Med Plant Stud 2015;3:49-57.

11. Rekha RW, Jayaraj RSC, Balu A. Variation in gas exchange characteristics in clones of Eucalyptus camaldulensis under varying conditions of $\mathrm{CO}_{2}$.J Stress Physiol Biochem 2013;9:33-4.

12. Kusari S, Verma VC, Lamshoeft M, Spiteller M. An endophytic fungus from Azadirachta indica A. Juss. that produces azadirachtin. World J Microbiol Biotechnol 2012;28:1287-94.

13. Gangwar M, Saini P, Kalia A. Diversity, anti-microbial and plant growth promoting the activity of endophytic actinomycetes isolated from Azadirachta indica A. Juss. Indian J Ecol 2016;43:101-10.

14. Narkhede MB. Evaluation of alpha-amylase inhibitory potential of four traditional culinary leaves. Asian J Pharm Clin Res 2012;5:75-6

15. Anam K, Widharna M, Kusrini D. Alpha-glucosidase inhibitor activity of Terminalia species. Int J Pharmacol 2009;5:277-80.

16. Gogoi N, Gogoi A, Neog B. Free radical scavenging activities of Garcinia xanthochymus Hook. F. and Garcinia lanceaefolia Roxb. using various in vitro assay models. Asian J Pharm Clin Res 2015;8:138-41.

17. Edwards CA, Black Burn NA, Craigne L, Daavidson P, Tomlin J Sugden $\mathrm{K}$, et al. Viscosity of food gums determined in vitro related to their hypoglycemic actions. Am J Clin Nutr 1987;46:72-7.

18. Nelson DL, Cox MM. Lehninger Principles of Biochemistry. 5th ed. New York: W. H. Freeman; 2008.

19. Jaiboon V, Boonyanupahap J, Suwansri S, Ratanatraiwong P, Hansawasdi C. Alpha-amylase inhibition and roasting time of local vegetables and herbs prepared for diabetes risk reduction chili paste. Asian J Food Agric India 2010;3:1-12.

20. Matsui T, Ogunwande IA, Abesundara KJM, Matsumoto K. Antihyperglycemic potential of natural products. Mini Rev Med Chem 2006;6:349-56. 
21. Ogunwande IA, Matsui T, Fujise T, Matsumoto K. $\alpha$-glucosidase inhibitory profile of nigerian medicinal plants in immobilized assay system. Food Sci Technol Res 2007;13:169-72.

22. Prabavthy D, Valli Nachiyar C. Antimicrobial and antidiabetic activity of an endophytic fungi isolated from Adathoda beddomei. Int J Pharm Pharm Sci 2013;5:780-3.

23. Shun W, Ruichang G. Screening of endophytic actinomycetes from medical plants with producing $\alpha$-amylase inhibitor. Chem Ind Eng Prog 2015;34:500-7.

24. Lestari Y, Velina Y, Rahminiwati M. Metabolites activity of endophytic Streptomyces sp. from Tinospora crispa: a $\alpha$ glucosidase inhibitor and anti-hyperglycemic in mice. Int J Pharm Pharm Sci 2015; 7:235-9.

25. Diaz-de-Cerio E, Verardo V, Gomez-Caravaca AM, FernandezGtierrez A, Segura-Carretero A. Exploratory characterization of phenolic compounds with demonstrated anti-diabetic in guava leaves at different oxidation states. Int J Mol Sci 2016;17:699.

26. Takahashi M, Miyashita M, Suzuki K, Bae SR, Kim HK, Wkisaka $\mathrm{T}$, et al. Acute ingestion of catechin-rich green tea improves postprandial glucose status and increases serum thioredoxin concentrations in postmenopausal women. Braz J Nutr 2014;112:1542-50.

27. Sumathy A, Keerthana G, Kalaivani MK. In vitro alpha-amylase inhibitory and antioxidant activities of ethanolic leaf extract of Croton bonplandianum. Asian J Pharm Clin Res 2013;6:32-6.

28. Sathiavelu A, Sundarmoorthy S, Rastogi A, Sathiavelu M. In vitro anti-diabetic activity of aqueous extract of the medicinal plants Nigella sativa, Eugenia jambolana, Andrographis paniculata and Gymnema sylvestre. Int J Drug Dev Res 2013;5:323-8.

29. Rey DP, Ospina LF, Aragón DM. Inhibitory effects of an extract of fruits of Physalis peruviana on some intestinal carbohydrases. Rev Colomb Cienc Quim Farm 2015;44:72-89.

\section{How to cite this article}

- Preeti Saini, Madhurama Gangwar, Amrinder Kaur. Bioactivities of the ethyl acetate extract of Rhodococcus qingshengii strain BJC15-A38 An endophyte of Azadirachta indica A. Juss. Int J Pharm Pharm Sci 2017;9(6):211-214. 